Titanium Anodization Efficiency Through Real-Time Gravimetric Measurement of Oxygen Evolution

To cite this article: D. Prando et al $2020 \mathrm{~J}$. Electrochem. Soc. 167061507

View the article online for updates and enhancements.

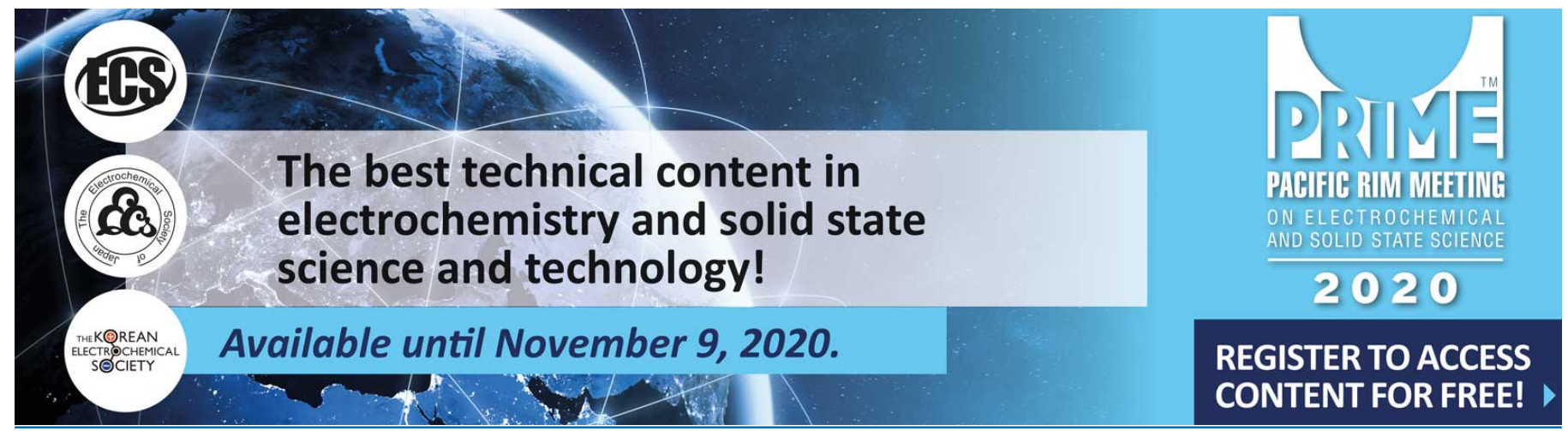




\title{
Titanium Anodization Efficiency Through Real-Time Gravimetric Measurement of Oxygen Evolution
}

\author{
D. Prando, ${ }^{1}$ S. Fajardo, ${ }^{2,3, *}$ M. Pedeferri, ${ }^{1}$ (i) and M. Ormellese ${ }^{1, z}$ (i) \\ ${ }^{1}$ Politecnico di Milano, Dipartimento di Chimica, Materiali e Ingegneria Chimica "G. Natta", Milano, Italy \\ ${ }^{2}$ Department of Surface Engineering, Corrosion and Durability (CENIM-CSIC), Madrid, Spain \\ ${ }^{3}$ Department of Chemistry, Universidad de La Laguna, Tenerife, La Laguna, Islas Canarias, Spain
}

\begin{abstract}
Anodization is an easy and reliable treatment to improve titanium corrosion resistance in severe environments. In previous studies, its effectiveness in enhancing oxide film resistance in halides was correlated with anodization cell voltage. To increase treatment industrial applicability, energy efficiency has to be maximized. For this purpose, a gravimetric approach was applied to study oxygen evolution during titanium anodic oxidation. Anodization efficiencies, calculated from real time $\mathrm{O}_{2}$ evolution measurements, were used to determine the most efficient galvanostatic anodization treatment by comparing different anodic current densities, from 1 to $20 \mathrm{~mA} \mathrm{~cm}{ }^{-2}$, and different electrolytes $\left(\mathrm{H}_{2} \mathrm{SO}_{4}-\mathrm{K}_{2} \mathrm{SO}_{4}\right)$. Anodization cell voltages were correlated with oxide thickness through indirect spectrophotometric measurements to compare the amount of charge needed to reach a certain film thickness in different anodization conditions.
\end{abstract}

(c) 2020 The Electrochemical Society (“ECS”). Published on behalf of ECS by IOP Publishing Limited. [DOI: 10.1149/1945-7111/ ab80d1]

Manuscript submitted January 20, 2020; revised manuscript received March 13, 2020. Published April 2, 2020.

Titanium and its alloys are worldwide appreciated for their superior corrosion resistance. This resistance is due to a thin $(1.5 \mathrm{~nm}-10 \mathrm{~nm})^{1}$ but compact and chemically stable oxide layer that is naturally formed when the metal is exposed to air. For this property, together with high strength, low density and high fracture toughness, ${ }^{2,3}$ they are applied in critical environments where even high-end stainless steels are not suitable (duplex UNS S31803 and UNS S32750 in concentrated chloride solution ${ }^{4,5}$ ). The application fields requiring titanium for its corrosion resistance range from offshore plants, acid environment, aerospace, ${ }^{6,7}$ automotive, high temperature, chemical and food industry, ${ }^{8-10}$ marine hydrometallurgical application and even nuclear fuel wastes containment. ${ }^{1,1}$-14

In such aggressive environments, even titanium may suffer different forms of corrosion. ${ }^{15,16}$ The most critical of them are due to the localized breaking of the passive layer, favored by the presence of concentrated halides, such as hot salty water (above $200{ }^{\circ} \mathrm{C}$ ) or bromide containing species. ${ }^{17,18}$ To further improve titanium corrosion resistance in these environments, specific treatments can be employed. Corrosion resistance enhancing treatments can be divided in two families: chemical composition changing treatments and oxide thickening treatments. The first family includes alloying with other elements (mainly $\mathrm{Pd}, \mathrm{Mo}$ and $\mathrm{Ni}$ ), ${ }^{19}$ nitration, ${ }^{20,21}$ vacuum plasma spray coating, plasma spray coating and chemical vapor deposition. ${ }^{22}$ Treatments of the second family rely on the possibility to thicken the naturally formed $\mathrm{TiO}_{2}$ film with an external electrical, chemical or thermal driving force, using anodic, chemical or thermal oxidation, respectively. Among them, anodization is the easiest, more reliable and precisely controllable. ${ }^{23-27}$ However, industrial application requires a balance of power consumption with productivity. In this scenario, it is vital to proceed in the most efficient way.

Anodizing efficiency, $\varepsilon$, can be estimated as the total charge provided to the system, $\mathrm{Q}_{\text {tot }}$,

$$
\varepsilon=\left(Q_{t o t}-Q_{O_{2}}\right) / Q_{t o t}
$$

This efficiency represents the cumulated efficiency to reach a certain anodizing voltage, averaged on the time required to reach it. The total charge supplied to the system is divided in two main reactions:

$$
\begin{gathered}
\mathrm{Ti} \rightarrow \mathrm{Ti}^{4+}+4 e^{-} \\
2 \mathrm{H}_{2} \mathrm{O} \rightarrow \mathrm{O}_{2}+4 \mathrm{H}^{+}+4 e^{-}
\end{gathered}
$$

Titanium oxidation (Eq. 2) may be slowed down or hindered by parasitic oxidation reactions (Eq. 3). Usually the anodization bath is properly chosen to prevent parasitic reactions other than water oxidation, such as chlorine oxidation if chlorides are present.

Assuming unitary efficiency, it is possible to calculate $\mathrm{TiO}_{2}$ film thickness from the electrical charge supplied to the system. As $\mathrm{TiO}_{2}$ is water insoluble, and considering it insoluble also in the electrolyte used for anodizing, the amount of $\mathrm{TiO}_{2}$ is calculated using the Faraday's law (Eq. 4):

$$
n=Q / Z F
$$

where $n$ is the number of moles reacted, $Q$ is the total charge passed, $Z$ is the number of electrons transferred per ions and $F$ is the Faraday constant. As $\mathrm{TiO}_{2}$ density, obtained by RBS and optical measurements, is $3.7 \mathrm{~g} \mathrm{~cm}^{-328} 1 \mathrm{C} \mathrm{cm}^{-2}$ would correspond to a $559 \mathrm{~nm}$ film in the absence of any parasitic reaction.

This calculation is used to indirectly obtain the anodization efficiency. By measuring the oxide thickness and knowing the amount of charge passed, it is possible to compare the theoretical oxide thickness in absence of any parasitic reaction with the real one. $^{29}$

With a more sophisticated approach, it is possible to directly measure the process efficiency. The amount of oxygen evolved from the anode during titanium anodic oxidation can be measured by a graduated cylinder put upside-down in the electrolyte above the anode. Evolved gas is collected in the cylinder and then its volume is converted to the amount of charge associated with the water oxidation reaction. ${ }^{30}$ This method, called volumetry, although more accurate than the indirect one, suffers some limitations:

- The minimum amount of evolved oxygen is limited by optical detection in the cylinder

- Measurement resolution is limited by graduated cylinder resolution

- Oxygen evolved from anode surface needs to physically detach from the surface and migrate into the cylinder to be detected

- Real-time measurement is very difficult.

To overcome these problems, another procedure, based on gravimetric measurements, can be applied. This method, introduced by Curioni et al., ${ }^{31}$ further developed by Fajardo and Frankel, ${ }^{32}$ consists of using a balance to record weight difference of a beaker 
placed upside-down over the anode. Even though this method has been commonly used for the assessment of hydrogen evolution rates, its applicability in oxygen collection during anodization experiments has also been shown. ${ }^{33}$ The efficiency of anodic oxidation treatments is also evaluated with the aim of increasing its industrial applicability. For this purpose, different applied current densities and anodization electrolytes were studied.

\section{Material and Methods}

Sample preparation.-Square samples $20 \times 20 \times 1.6 \mathrm{~mm}^{3}$ were obtained from titanium UNS R50400 (ASTM grade 2) sheet. After manual abrasion with 800 grit $\mathrm{SiC}$ paper in two perpendicular directions, each sample was degreased in $\mathrm{EtOH}$ and soldered on the back to an electrical wire. Then, the whole sample except the nonsoldered face was cold mounted in epoxy-resin in order to keep the possibility to polarize the sample when fully immersed in the electrolyte, without exposing any other metal to the bath.

Gravimetric test setup.-Oxygen evolution measurements were carried out during galvanostatic anodization in a conventional twoelectrode electrochemical cell $(800 \mathrm{ml})$ with a Pt mesh acting as the counter-electrode. The applied current densities were 5, 10, 15 and $20 \mathrm{~mA} \mathrm{~cm}{ }^{-2}$. The test solution was $0.5 \mathrm{M} \mathrm{H}_{2} \mathrm{SO}_{4}$. Additionally, oxygen evolution measurements were also performed in $0.5 \mathrm{M}$ $\mathrm{K}_{2} \mathrm{SO}_{4}$ solution at an applied anodic current density of $10 \mathrm{~mA} \mathrm{~cm}$. Anodic oxidation was stopped when cell voltage reached $120 \mathrm{~V}$ in all cases except at $5 \mathrm{~mA} \mathrm{~cm}^{-2}$, where the low current density applied did not allow to reach that voltage in reasonable experimental time. In that case, $100 \mathrm{~V}$ was taken as the limiting value. The current was supplied by an AimTTi PLH120 DC power supply, which allows polarization up to $120 \mathrm{~V}$ and $0.75 \mathrm{~A}$.

A Gamry Instruments Interface $1000 \mathrm{E}$ potentiostat/galvanostat controlled by the Gamry Framework was used to investigate the early stages of anodization. This allowed for a higher accuracy in the current supplied and the cell voltage reached. In this case, galvanostatic polarization measurements were conducted at an applied current density of $1 \mathrm{~mA} \mathrm{~cm}^{-2}$ until a voltage of $12 \mathrm{~V}$ was reached. The test solution was $0.5 \mathrm{M} \mathrm{H}_{2} \mathrm{SO}_{4}$

All the experiments were performed at least in duplicate to ensure reproducibility. Room temperature was kept between $23{ }^{\circ} \mathrm{C}$ and $25^{\circ} \mathrm{C}$, the exact temperature was recorded prior of each experiment for oxygen volume/moles conversion. Solution temperature was confirmed not to change during the experiment by measuring final temperature close to the anodized sample.

Solutions $\mathrm{pH}$ was measured before and after anodizing experiments using a Crison GLP22 $\mathrm{pH}$ meter. The measured $\mathrm{pH}$ of the $\mathrm{H}_{2} \mathrm{SO}_{4}$ solution was 0.5 . No meaningful variation in the $\mathrm{pH}$ was observed after the anodization experiments. The initial $\mathrm{pH}$ of the $\mathrm{K}_{2} \mathrm{SO}_{4}$ solution was 5.3 . This value did no show any significant variation after four anodizations.

The gravimetric oxygen evolution measurement setup is described elsewhere ${ }^{32}$ An inverted glass beaker was attached to a wire hanging from the bottom of a Mettler Toledo balance (model MS204S) with an accuracy of $10^{-4} \mathrm{~g}$. A titanium sample was inserted in the beaker, where all the oxygen produced at the anode surface was collected, causing a decrease in recorded weight. The weight difference associated with the hydrostatic force exerted by the accumulation of gas in a submerged vessel, allowed $\mathrm{O}_{2}$ detection with higher sensitivity than the volumetric method.

Setup resolution.-The setup resolution was calculated at the laboratory physical condition of pressure and temperature. The barometric pressure during first experiment was $101.3 \mathrm{kPa}$ and the temperature was $23.6{ }^{\circ} \mathrm{C}$.

Considering $1.022 \mathrm{~g} \mathrm{~cm}^{-3}$ to be the density of $0.5 \mathrm{M} \mathrm{H}_{2} \mathrm{SO}_{4}$, the oxygen evolution rate, responsible for $0.1 \mathrm{mg} \mathrm{s}^{-1}$ (balance resolution) of weight decrease rate, is $4.019 \cdot 10^{-9} \mathrm{~mol} \mathrm{~s}^{-1}$, the latter being the minimum detectable oxygen evolution rate. Using Faraday's
Law, this corresponds to a current resolution of $1.552 \mathrm{~mA}$, which is the minimum current associated with oxygen evolution detectable by this experimental setup.

As the beaker is immersed below the electrolyte free surface, the gas pressure inside the beaker differs from the barometric pressure. Fajardo and Frankel ${ }^{32}$ considered this difference and, being in the order of $10^{-4} \mathrm{~atm}$, it may be neglected.

Measure calibration.-Prior to any measurement, a setup calibration was performed. A high purity platinum electrode was used as an anode to avoid any metal oxidation reaction. In this way, all the current supplied by the feeder produces oxygen evolution, allowing a comparison between the current provided by the power supply and the current responsible for oxygen evolution obtained by gravimetric measurement of evolved oxygen. This comparison leads to setup efficiency and accuracy estimation.

Film thickness measurement.-The described setup allows not only to record oxygen evolved from the anode at the end of each experiment, but a real-time measurement during anodization. Thus, efficiency can be monitored not only as a function of time, but also as a function of cell voltage reached at a certain time. However, efficiencies of anodic oxidation in different electrolytes have to be compared as a function of oxide thickness achieved, and not as a function of the cell voltage reached, because the anodizing bath might have an influence on the relation cell voltage/oxide thickness relation.

To compare the results obtained in $0.5 \mathrm{M} \mathrm{H}_{2} \mathrm{SO}_{4}$ and $0.5 \mathrm{M}$ $\mathrm{K}_{2} \mathrm{SO}_{4}$ solutions, anodizations were repeated and stopped at the following cell voltages: $5,10,15,20,25,30,35,40,50,60,70,80$, 90,100 and $120 \mathrm{~V}$. Oxide thicknesses were obtained by indirect spectrophotometric analyses, ${ }^{34}$ using a Konica-Minolta spectrophotometer CM-2500d to measure the wavelength corresponding to maxima and minima of interference in reflected white-light spectrum. By using an internally developed tool based on the works of Kischkat et al., ${ }^{35}$ Siefke et al. ${ }^{36}$ and Abdellatif et al. ${ }^{37}$ to calculate $\mathrm{TiO}_{2}$ refractive index, the computation of the film thickness is possible.

\section{Results}

Measure calibration results.-Results of the setup calibration are visible in Fig. 1. After an initial transient in which system inertia is dissipated, oxygen evolution on platinum electrode reaches a steady state using approximately $95 \%$ of the total charge provided from the power supply. As platinum anode cannot be anodized and no reactions other than oxygen evolution are involved, the expected amount of charge used for this reaction is $100 \%$. Thus, the gravimetric setup used for these measurements has an intrinsic error of about $5 \%$.

Anodization kinetics.-Cell voltage growth during galvanostatic anodization in $0.5 \mathrm{M} \mathrm{H}_{2} \mathrm{SO}_{4}$ and $0.5 \mathrm{M} \mathrm{K}_{2} \mathrm{SO}_{4}$ solutions at applied current densities ranging from 5 to $20 \mathrm{~mA} \mathrm{~cm}^{-2}$ is shown in Fig. 2.

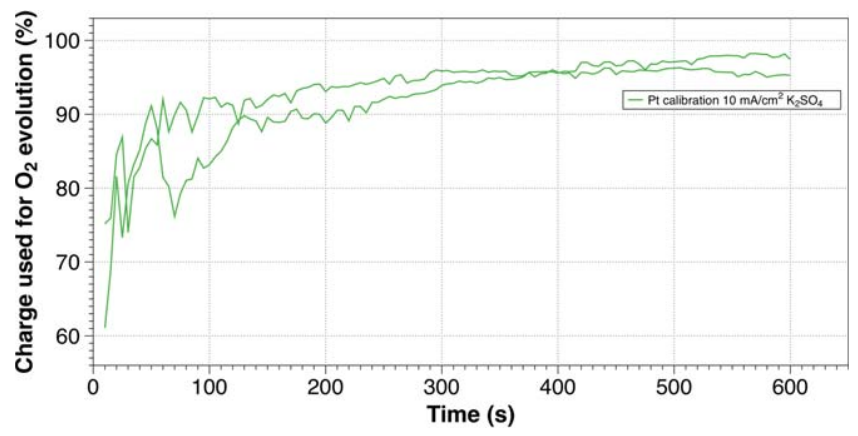

Figure 1. Setup calibration results. $\mathrm{Pt}$ anode polarized at $10 \mathrm{~mA} \mathrm{~cm}^{-2}$. 


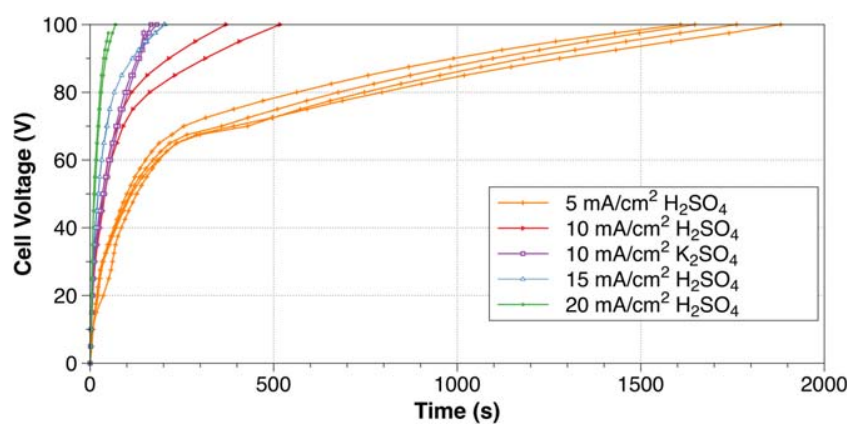

Figure 2. Cell voltage growth kinetic during galvanostatic anodization in $\mathrm{H}_{2} \mathrm{SO}_{4}$ and $\mathrm{K}_{2} \mathrm{SO}_{4}$ at different current density.

As expected, using the same electrolyte, higher current density leads to faster anodization. Moreover, at increasing current density, the voltage range in which voltage growth deviates from linearity shifts at higher values: from about $60-70 \mathrm{~V}$ at $5 \mathrm{~mA} \mathrm{~cm}^{-2}$ to $100 \mathrm{~V}$ at $20 \mathrm{~mA} \mathrm{~cm}^{-2}$.

It is also important to notice that different electrolytes lead to different anodization kinetics. $0.5 \mathrm{M} \mathrm{K}_{2} \mathrm{SO}_{4}$ showed faster voltage growth compared to sulphuric acid at the same current density. The sample anodized in $0.5 \mathrm{M} \mathrm{K}_{2} \mathrm{SO}_{4}$ solution at $10 \mathrm{~mA} \mathrm{~cm}^{-2}$ required the same time to reach $100 \mathrm{~V}$ as that the one anodized at $15 \mathrm{~mA} \mathrm{~cm}^{-2}$ in $0.5 \mathrm{M} \mathrm{H}_{2} \mathrm{SO}_{4}$. However, analyzing more in details these two samples, potassium sulphate showed deviation from linearity at higher voltage, leading to a slower growth below $90 \mathrm{~V}$ and faster above this value, which corresponds to the first appearance of anodic sparks due to $\mathrm{TiO}_{2}$ dielectric breakdown in the anodic spark deposition regime. The same trend is observed at lower voltages and current densities. Figure 3 shows galvanostatic anodization at $1 \mathrm{~mA} \mathrm{~cm}^{-2}$ in $0.5 \mathrm{M} \mathrm{K}_{2} \mathrm{SO}_{4}$ and $0.5 \mathrm{M} \mathrm{H}_{2} \mathrm{SO}_{4}$ : the latter promoted a slower anodization and deviated from linearity at voltages lower than potassium sulphate.

Anodization efficiency.-Anodization efficiencies at different current densities were obtained as described in Eq. 1. Results are plotted in Fig. 4 as a function of the measured cell voltage. All the conditions tested operate at $100 \%$ efficiency up to a certain voltage, which increases as anodization current density increases. Anodization tests carried out at $5 \mathrm{~mA} \mathrm{~cm} \mathrm{~cm}^{-2}$ kept $100 \%$ efficiency until $15 \mathrm{~V}$ was reached, while anodization at $20 \mathrm{~mA} \mathrm{~cm}^{-2}$ reached $35 \mathrm{~V}$ before efficiency started to decrease. However, a plateau in efficiency is reached at high cell voltage for current density lower than $20 \mathrm{~mA} \mathrm{~cm}$ and this plateau is higher at lower current densities.

The effect of $0.5 \mathrm{M} \mathrm{K}_{2} \mathrm{SO}_{4}$, compared to $0.5 \mathrm{M} \mathrm{H}_{2} \mathrm{SO}_{4}$, is to increase the voltage at which efficiency starts to decrease and to reach $100 \mathrm{~V}$ at lower efficiency values. In the presence of sulphuric acid the same trend at higher current density was observed. This is in agreement with the anodization kinetics shown in Fig. 2.

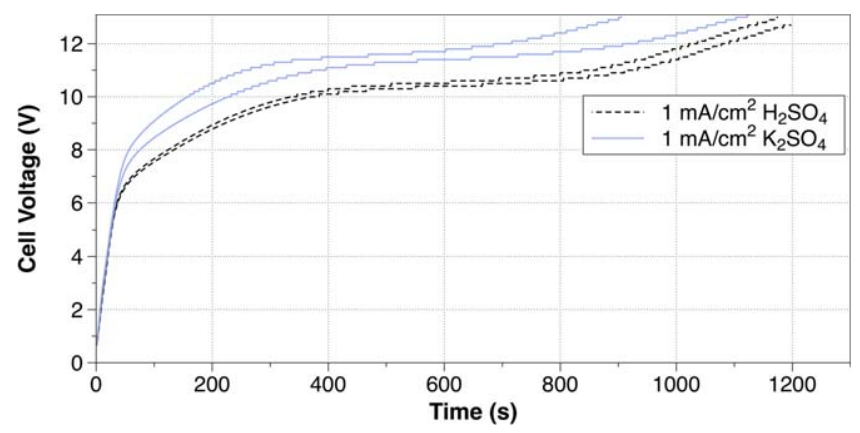

Figure 3. Cell voltage growth kinetic during galvanostatic anodization in $\mathrm{H}_{2} \mathrm{SO}_{4}$ and $\mathrm{K}_{2} \mathrm{SO}_{4}$ solutions at an applied current density of $1 \mathrm{~mA} \mathrm{~cm}{ }^{-2}$.

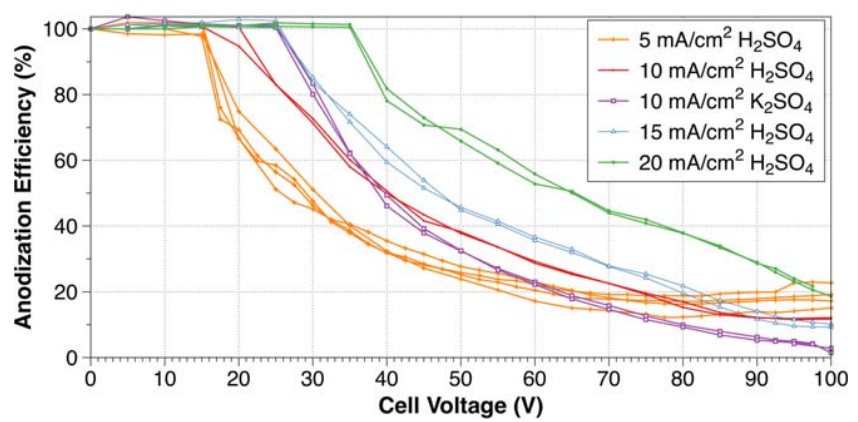

Figure 4. Anodizing efficiency vs cell voltage reached at different current densities and different electrolytes.

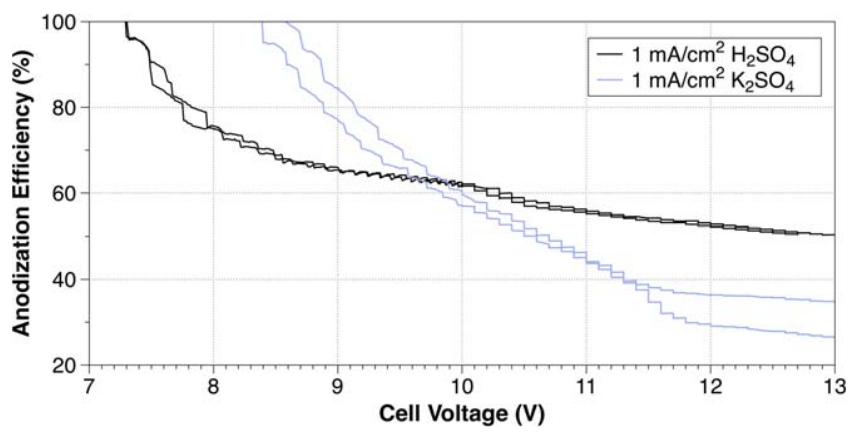

Figure 5. Anodizing efficiency vs cell voltage during anodization at $1 \mathrm{~mA} \mathrm{~cm}{ }^{-2}$ in different electrolytes.

The same behavior was maintained at lower current density $\left(1 \mathrm{~mA} \mathrm{~m}^{-2}\right)$ and lower final cell voltage. Results are reported in Fig. 5. Anodizations carried out in $0.5 \mathrm{M} \mathrm{K}_{2} \mathrm{SO}_{4}$ shows higher efficiency at lower voltage and lower efficiency as voltage increases.

As most of the anodizing time was spent at high voltages, where voltage growth rate decreases, the efficiency plateau becomes more evident when plotted as a function of polarization time. However, it is important to remember that oxide thickness is proportional to anodizing cell voltage and that the amount of time spent to reach a certain voltage has a negligible effect on the corresponding thickness reached. In Fig. 6, the evolution of efficiency with time is shown for anodizations carried out at different current densities, in the two considered electrolytes.

After about $100 \mathrm{~s}$, efficiency decreases to a level that is maintained until a further deviation is observed. This has been associated with the transition from standard anodization regime to anodic spark deposition, with consequent dielectric breakdown of the oxide film and further decrease in efficiency below the plateau value. Anodizations carried out at $20 \mathrm{~mA} \mathrm{~cm}^{-2}$ reached anodic spark deposition before $100 \mathrm{~s}$, so no plateau was observed. In all the other

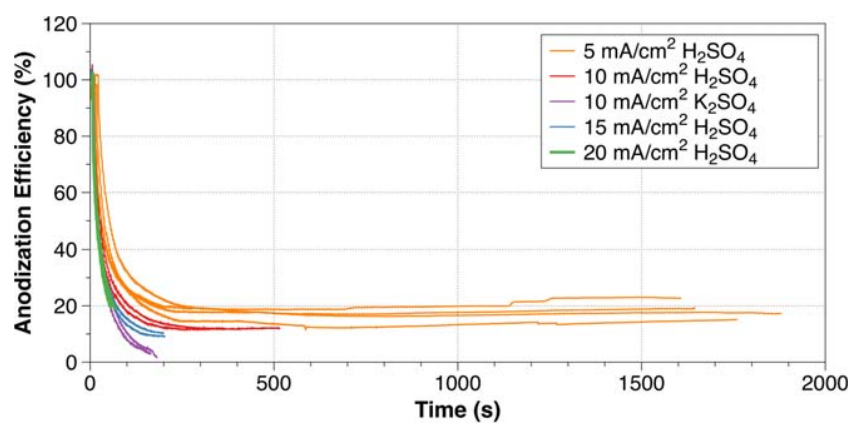

Figure 6. Anodizing efficiency vs time during anodization in different current densities and different electrolytes. 


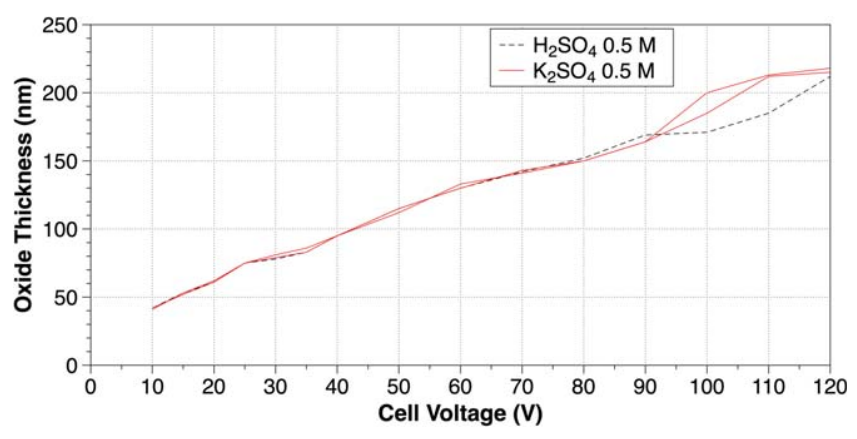

Figure 7. Thickness of $\mathrm{TiO}_{2}$ obtained with anodization in $\mathrm{H}_{2} \mathrm{SO}_{4} 0.5 \mathrm{M}$ and $\mathrm{K}_{2} \mathrm{SO}_{4} 0.5 \mathrm{M}$ at different cell voltages from $10 \mathrm{~V}$ to $120 \mathrm{~V}$.

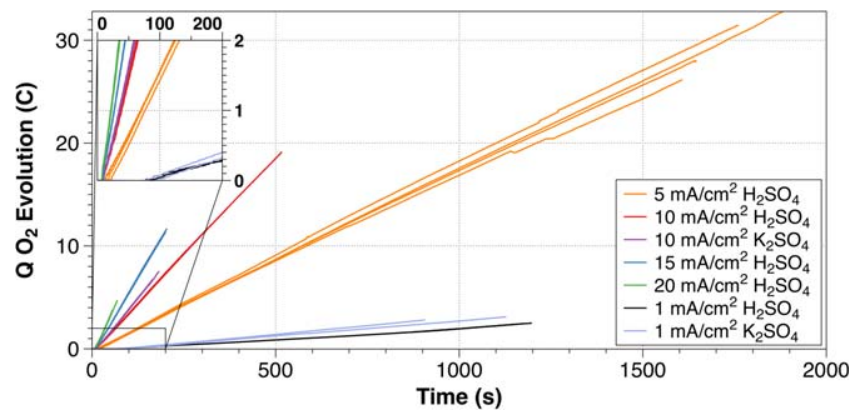

Figure 8. Charge associated with $\mathrm{O}_{2}$ evolution vs time during anodization at different current densities and in different electrolytes.

cases, the plateau value decreased as anodizing current density increased.

Oxide thickness.-In Figs. 4 and 5, previously commented, the efficiency was compared to the final cell voltage. However, comparisons between different electrolytes are subjected to the hypothesis that the same cell voltage corresponds to the same oxide thickness. To confirm this hypothesis, anodizations were carried out in a voltage range from $10 \mathrm{~V}$ to $120 \mathrm{~V}$, being one series of samples anodized using $0.5 \mathrm{M} \mathrm{H}_{2} \mathrm{SO}_{4}$ solution, for which more data are available in literature ${ }^{38-43}$ and in unpublished data from this research group, and two series using $0.5 \mathrm{M} \mathrm{K}_{2} \mathrm{SO}_{4}$ as electrolyte to ensure repeatability. Results are shown in Fig. 7.

Up to $90 \mathrm{~V}$, the thicknesses of oxides produced in the two electrolytes were nearly identical. At a cell voltage greater than $90 \mathrm{~V}$ significant differences were observed. This was due to the onset of the anodic spark deposition regime, in which more oxygen is developed. This resulted in a less controlled phenomenon and in a decrease in reproducibility.

Oxide film thickness was also used to calculate the influence of oxide volume on gravimetric setup measurements. The oxide growing at metal surface changes the sample volume and weight, hence modifying the hydrostatic force exerted by the sample on the scale, leading to possible errors during $\mathrm{O}_{2}$ evolution measurement. Two opposite contributions have to be considered, i.e. the modification of hydrostatic force and the increase in weight due to oxide growth. As Pilling-Bedworth ratio for titanium is 1.73 , a $220 \mathrm{~nm}$ thick oxide, the maximum thickness obtain by spectrophotometric measurements, corresponds to a metal thickness $127 \mathrm{~nm}$ of metal oxidized to $\mathrm{TiO}_{2}$. For these $127 \mathrm{~nm}$, the transformation from metal to oxide caused a change in density, with a consequent weight variation of approximately $-4 \cdot 10^{-5} \mathrm{~g}$. The remaining $93 \mathrm{~nm}$ of oxide thickness not covered by the previously present metal, hence freshly grown, being the sample surface equal to $4 \mathrm{~cm}^{2}$, led to an increase in volume of $3.72 \cdot 10^{-5} \mathrm{~cm}^{3}$ with density $3.7 \mathrm{~g} \mathrm{~cm}^{-3}$ and weight 1.4 . $10^{-4} \mathrm{~g}$. As the electrolyte density is $1.022 \mathrm{~g} \mathrm{~cm}^{-3}$, the volume in excess caused a hydrostatic force of $9.9 \cdot 10^{-5} \mathrm{~g}$ due to the hydrostatic force modification during the whole experiment. Considering weight variation and hydrostatic force increase, the total weight error is in the order of $1 \cdot 10^{-6} \mathrm{~g}$. As this value is quite below the setup experimental error, the effect of weight and volume variation was considered negligible.

\section{Discussion}

Oxygen evolution interpolated efficiency.-In Fig. 8 the charge associated with oxygen evolution is plotted as a function of polarization time. A linear-like behavior can be observed. Linearity started from the first non-zero value and was maintained until a cell voltage around $100 \mathrm{~V}$ was reached, where anodic spark deposition became relevant. The first non-zero measurement appeared after about $10 \mathrm{~s}$ from the beginning of the experiment, independently of the current density applied. This behavior is ascribed to the existence of a measurement inertia characteristic of the experimental setup used and confirmed by Figs. 4 and 6 . The effect of this inertia is to associate an efficiency of $100 \%$ to the first seconds of anodization. This affects the cumulative efficiency of the experiment until the amount of data collected are enough to hide the initial error. This is coherent with the characteristic time necessary to the efficiency to reach a plateau. The slope of $\mathrm{O}_{2}$ evolution associated charge vs time, which is the current spent in oxygen evolution parasitic reaction, is a more reliable measurement of process efficiency, with respect to cumulative efficiency (Fig. 8).

Table I. Anodizing efficiencies calculated by plotting charge associated with oxygen evolution against time.

\begin{tabular}{|c|c|c|c|}
\hline Electrolyte & Anodizing current density $\left(\mathrm{mA} \mathrm{cm}{ }^{-2}\right)$ & $\mathrm{O}_{2}$ evolution current density $\left(\mathrm{mA} \mathrm{cm}{ }^{-2}\right)$ & Efficiency $(\%)$ \\
\hline \multirow{12}{*}{$\mathrm{H}_{2} \mathrm{SO}_{4}$} & 20 & 15.6 & 23.0 \\
\hline & & 15.3 & 23.5 \\
\hline & 15 & 14.1 & 6.3 \\
\hline & & 13.8 & 8.0 \\
\hline & 10 & 9.2 & 7.7 \\
\hline & & 9.2 & 7.7 \\
\hline & 5 & 4.5 & 9.5 \\
\hline & & 4.4 & 12.9 \\
\hline & & 4.3 & 14.0 \\
\hline & & 4.1 & 17.4 \\
\hline & 1 & 0.57 & 52.5 \\
\hline & & 0.47 & 52.6 \\
\hline \multirow[t]{4}{*}{$\mathrm{K}_{2} \mathrm{SO}_{4}$} & 10 & 9.77 & 2.3 \\
\hline & & 9.80 & 2.0 \\
\hline & 1 & 0.66 & 34.3 \\
\hline & & 0.73 & 27.1 \\
\hline
\end{tabular}




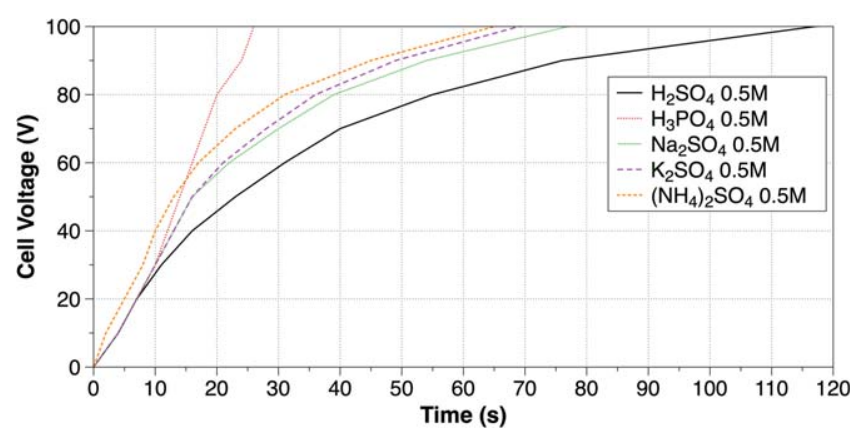

Figure 9. Anodizations kinetics in acid and neutral electrolytes at $10 \mathrm{~mA} \mathrm{~cm}^{-2}$.

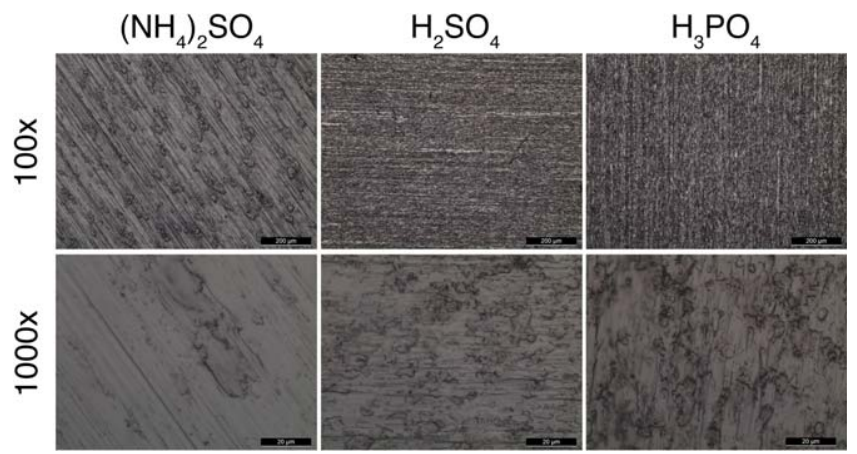

Figure 10. Surface morphology of naturally oxidized samples after submersion tests in $\left(\mathrm{NH}_{4}\right)_{2} \mathrm{SO}_{4} 0.5 \mathrm{M}, \mathrm{H}_{2} \mathrm{SO}_{4} 0.5 \mathrm{M}$ and $\mathrm{H} 3 \mathrm{PO} 40.5 \mathrm{M}$.

The efficiencies calculated using linear fitting of data presented in Fig. 8 are shown in Table I. Efficiency remained constant during the whole anodization treatment until the anodic spark deposition regime was established. In standard anodization conditions, it is possible to compare the efficiency obtained at different current density, regardless of cell voltage. Anodization efficiency increased as current density decreased, passing from $23 \%$ at $20 \mathrm{~mA} \mathrm{~cm}^{-2}$ to $52 \%$ at $1 \mathrm{~mA} \mathrm{~cm}^{-2}$. The same trend was observed in both $0.5 \mathrm{M}$ $\mathrm{H}_{2} \mathrm{SO}_{4}$ and $0.5 \mathrm{M} \mathrm{K}_{2} \mathrm{SO}_{4}$ solutions.

Potassium sulphate efficiency and kinetics.-Table I shows that anodizations carried out at $10 \mathrm{~mA} \mathrm{~cm}^{-2}$ in $0.5 \mathrm{M} \mathrm{H}_{2} \mathrm{SO}_{4}$ solution exhibited efficiency values about $5 \%$ higher than those performed in $0.5 \mathrm{M} \mathrm{K}_{2} \mathrm{SO}_{4}$ solution. These results are in disagreement with the anodization kinetics observed in Fig. 3. Potassium sulphate leads to a faster anodization compared to sulphuric acid, but the amount of oxygen produced during anodization was higher, suggesting that a smaller fraction of the available charge was consumed by the film growth.

It is possible that sulphuric acid leads to a faster oxide growth, but simultaneously caused a non-negligible amount of oxide dissolution due to the high solution acidity, resulting in a slower net oxide growth kinetics compared with potassium sulphate. To confirm this hypothesis, anodization kinetics were studied in different electrolytes up to $100 \mathrm{~V}$, so avoiding anodic spark deposition. The tested solutions were $0.5 \mathrm{M} \mathrm{H}_{2} \mathrm{SO}_{4}(\mathrm{pH} 0.5), 0.5 \mathrm{M} \mathrm{H}_{3} \mathrm{PO}_{4}$ (pH 1), 0.5 M Na $2 \mathrm{SO}_{4}\left(\mathrm{pH} \mathrm{7)}, 0.5 \mathrm{M} \mathrm{K}_{2} \mathrm{SO}_{4}(\mathrm{pH}\right.$ 7) and $0.5 \mathrm{M}$ $\left(\mathrm{NH}_{4}\right)_{2} \mathrm{SO}_{4}(\mathrm{pH} 6)$. Results are shown in Fig. 9.

The sulphate salts, in almost neutral condition, led to a faster anodization compared to $\mathrm{H}_{2} \mathrm{SO}_{4}$. This is consistent with the hypothesis that $\mathrm{pH}$ has a strong influence on anodization kinetics regardless of to the amount of charge consumed by oxygen evolution. $\mathrm{H}_{3} \mathrm{PO}_{4}$ showed different oxide growth kinetics. Up to $50 \mathrm{~V}$, the trend reassembled that observed when sulphates solutions were used. However, at higher voltages no decrease in kinetics was observed up to $100 \mathrm{~V}$. As reported by Liu et al., ${ }^{44}$ the faster kinetics in phosphoric acid was due to the inhibition of amorphous-tocrystalline transition, which leads to a lower number of crystalline sites at which oxygen evolution develops, resulting in a smaller amount of oxide blisters.

As a further confirmation, a 24 hour-long immersion test was performed: a non-anodized sample was immersed in each solution and then rinsed and observed in an optical microscope. Results are visible in Fig. 10.

Neutral electrolytes (such as $\left(\mathrm{NH}_{4}\right)_{2} \mathrm{SO}_{4}$ reported in the figure), did not cause any surface modification visible in the optical microscope. In contrast, both sulfuric and phosphoric acid etched the surface making difficult to distinguish polishing marks at low magnification. At higher magnification, surface features density of samples exposed to acid electrolytes is higher compared to the one of sample exposed to neutral electrolyte. Although these results agreed with literature data, ${ }^{3,45,46}$ in this case no polarization is applied and this experiment does not replicate the condition occurring while anodizing has been performed. However, it demonstrates the higher capability of the acid solution to etch $\mathrm{TiO}_{2}$ film.

\section{Conclusions}

In this study, a gravimetric experimental setup was used to measure the amount of $\mathrm{O}_{2}$ evolved during anodization on commercially pure titanium. The purpose was to calculate anodization efficiency dependence on anodization current density, anodization voltage and electrolyte by calculating the amount of charge dissipated in $\mathrm{O}_{2}$ evolution, thus, obtaining the charge effectively responsible for oxide growth.

The main conclusions are as follow:

- Galvanostatic anodization kinetics were studied in $0.5 \mathrm{M}$ $\mathrm{H}_{2} \mathrm{SO}_{4}$ at current densities ranging from 1 to $20 \mathrm{~mA} \mathrm{~cm}{ }^{-2}$ and compared with $0.5 \mathrm{M} \mathrm{K}_{2} \mathrm{SO}_{4}$. Potassium sulfate led to faster anodization compared to sulfuric acid at the same current density.

- Anodization efficiency was studied with real-time $\mathrm{O}_{2}$ evolution measurement using the gravimetric method. Lower current densities led to higher efficiency, up to $52 \%$ at $1 \mathrm{~mA} \mathrm{~cm}^{-2}$ in $0.5 \mathrm{M} \mathrm{H}_{2} \mathrm{SO}_{4}$ that remained constant up to the anodic spark deposition regime establishment. Higher current densities led to lower efficiency, about $23 \%$ at $20 \mathrm{~mA} \mathrm{~cm}^{-2}$ in the same electrolyte. Potassium sulfate showed an efficiency $10 \%$ lower if compared to sulfuric acid at both $1 \mathrm{~mA} \mathrm{~cm}^{-2}$ and $10 \mathrm{~mA} \mathrm{~cm}{ }^{-2}$.

- The disagreement between the faster kinetics of anodizations carried out in $\mathrm{K}_{2} \mathrm{SO}_{4}$ solution, compared to those carried out in $\mathrm{H}_{2} \mathrm{SO}_{4}$ solution, and their lower efficiency was justified by the effect of the different $\mathrm{pH}$ of the two solutions. To confirm the relation between solution $\mathrm{pH}$ and anodization kinetics, anodic oxidations were carried out in three sulfate salts, with an almost neutral $\mathrm{pH}$. All of them showed kinetics faster than the one observed using $\mathrm{H}_{2} \mathrm{SO}_{4}$ solution as electrolyte.

\section{ORCID}

M. Pedeferri (ID https://orcid.org/0000-0001-9206-4869

M. Ormellese (iD https://orcid.org/0000-0003-1546-1072

\section{References}

1. D. Prando et al., Journal of Applied Biomaterials \& Functional Materials, 15, e19 (2017)

2. D. Banerjee and J. C. Williams, Acta Mater., 61, 844 (2013).

3. M. J. Donachie, Titanium: A Technical Guide (ASM International, United States of America) 2nd ed. (2000).

4. A. Alfantazi, E. Asselin, and J. Liu, NACE 2016, 7135 (2016).

5. B. Deng et al., Electrochim. Acta, 53, 5220 (2008).

6. R. R. Boyer, Mater. Sci. Eng. A, 213, 103 (1996).

7. S. Y. Chang, H. K. Lin, L. C. Tsao, W. T. Huang, and Y. T. Huang, Corrosion Engineering, Science and Technology, 49, 17 (2014).

8. D. Eylon, Titanium for Energy and Industrial Applications (Metallurgical Society of AIME, United States of America) (1981). 
9. F. H. Froes, D. Eylon, and H. B. Bomberger, Titanium technology: Present status and future trends (Titanium Development Association, United States of America) (1985).

10. S. Virtanen, Corros. Rev, 26, 147 (2008).

11. I. V. Gorynin, Mater. Sci. Eng. A, 263, 112 (1999).

12. J. C. Griess, Corrosion, 24, 96 (1968).

13. J. Liu, A. Alfantazi, and E. Asselin, Corrosion, 70, 29 (2014).

14. D. W. Shoesmith, D. Hardie, B. M. Ikeda, and J. J. Noel, (1997), http://inis.iaea org/Search/search.aspx?orig_q=RN:30039707 Hydrogen Absorption and the Lifetime Performance of Titanium Nuclear Waste ContainersAtomic Energy of Canada Limited.

15. D. Prando et al., Journal of Applied Biomaterials \& Functional Materials, 16, 3 (2018).

16. R. W. Schutz, Corrosion of Titanium and Titanium Alloys, Corrosion: Materials (ASM International, United States of America) (2005).

17. T. R. Beck, J. Electrochem. Soc., 120, 1317 (1973).

18. D. Prando, D. Nicolis, M. Pedeferri, and M. Ormellese, Mater. Corros., 69, 1441 (2018).

19. P. Handzlik and K. Fitzner, Transactions of Nonferrous Metals Society of China, 23, 866 (2013)

20. G. C. L. B. Neto, M. A. M. da Silva, and J. C. Alves, Surf. Eng., 25, 146 (2009)

21. S. Sathish, M. Geetha, N. D. Pandey, C. Richard, and R. Asokamani, Materials Science and Engineering: C, 30, 376 (2010).

22. E. Vetrivendan, J. Jayaraj, S. Ningshen, C. Mallika, and M. Kamachi, J. Therm. Spray Technol., 27, 512 (2018).

23. N. Khalil and J. S. L. Leach, Electrochim. Acta, 31, 1279 (1986)

24. J. W. Schultze, M. M. Lohrengel, and D. Ross, Electrochim. Acta, 28, 973 (1983).

25. J. W. Schultze and M. M. Lohrengel, Electrochim. Acta, 45, 2499 (2000).

26. A. K. Sharma, Thin Solid Films, 208, 48 (1992)
27. D. Prando, A. Brenna, M. Pedeferri, and M. Ormellese, Mater. Corros., 69, 503 (2017).

28. M. Laube, F. Rauch, C. Ottermann, O. Anderson, and K. Bange, Nucl. Instrum Methods Phys. Res., Sect. B, 113, 288 (1996).

29. A. Valota et al., Nanotechnology, 19, 355701 (2008).

30. J.-L. Delplancke and R. Winand, Electrochim. Acta, 33, 1551 (1988)

31. M. Curioni, Electrochim. Acta, 120, 284 (2014)

32. S. Fajardo and G. S. Frankel, J. Electrochem. Soc., 162, C693 (2015).

33. J. M. Torrescano-Alvarez, M. Curioni, and P. Skeldon, J. Electrochem. Soc., 164 C728 (2017).

34. M. V. Diamanti, F. C. Spreafico, and M. P. Pedeferri, Phys. Proc., 40, 30 (2013).

35. J. Kischkat et al., Appl. Opt., 51, 6789 (2012).

36. T. Siefke et al., Adv. Opt. Mater., 4, 1780 (2016).

37. S. Abdellatif et al., Microporous Mesoporous Mater., 264, 84 (2018)

38. A. Karambakhsh, A. Afshar, S. Ghahramani, and P. Malekinejad, J. Mater. Eng Perform., 20, 1690 (2011).

39. J.-L. Delplancke and R. Winand, Electrochim. Acta, 33, 1539 (1988).

40. D. J. Blackwood and L. M. Peter, Electrochim. Acta, 34, 1505 (1989).

41. J. R. Birch and T. D. Burleigh, Corrosion, 56, 1233 (2000).

42. A. Mazzarolo, M. Curioni, A. Vicenzo, P. Skeldon, and G. E. Thompson, Electrochim. Acta, 75, 288 (2012).

43. D. Prando, M. Pedeferri, A. Brenna, and M. Ormellese, NACE-International Corrosion Conference Series, 3, 1606 (2017)

44. Z. J. Liu, X. Zhong, J. Walton, and G. E. Thompson, J. Electrochem. Soc., 163, E75 (2016).

45. S. Ban, Y. Iwaya, H. Kono, and H. Sato, Dent. Mater, 22, 1115 (2006).

46. H. Z. Abdullah and C. C. Sorrell, Advanced Materials Research, 545, 223 (2012). 